\title{
Polycyclic aromatic hydrocarbon in urban soil from Beijing, China
}

\author{
LI Xing-hong ${ }^{1}$, MA Ling-ling ${ }^{1}$, LIU Xiu-fen ${ }^{1}$, FU Shan ${ }^{1}$, CHENG Hang-xin ${ }^{2}$, XU Xiao-bai ${ }^{1 * *}$ \\ 1. State Key Laboratory of Environmental Chemistry and Ecotoxicology, Research Center for Eco-Environmental Sciences, Chinese Academy of \\ Sciences, Beijing 100085, China. E-mail: xuxb@public.bta.net.cn; 2. Institute of Geophysical and Geochemical Exploration, Langfang 065000, China)
}

\begin{abstract}
Polycyclic aromatic hydrocarbons (EPA-PAHs) in the urban surface soils from Beijing were determined using gas chromatography and mass spectrometry (GC-MS). It is significantly complementary for understanding the PAHs pollution in soil of integrated Beijing city on the basis of the information known in the outskirts. The total concentration of 16 EPA-PAH was from 0.467 to $5.470 \mu \mathrm{g} / \mathrm{g}$ and was described by the contour map. Compound profiles presented that the 4-, 5- and 6-ring PAHs were major compositions. The correlation analysis showed that PAHs have the similar source in the most sampling sites and BaP might be considered as the indicator of PAHs. Characteristic ratios of anthracene (An)/(An+ phenanthrene (Phe)), fluoranthene (Flu)/(Flu+ pyrene (Pyr)) and benzo[a]pyrene (BaP)/benzo[g,h,i]perylene (BghiP) indicated that the PAHs pollutants probably mainly originated from the coal combustion and it was not negligible from vehicular emission. The level of PAHs in our study area was compared with other studies.
\end{abstract}

Keywords: PAHs; urban soil; source; Beijing

\section{Introduction}

Polycyclic aromatic hydrocarbons (PAHs) in the environment are attracting increasing attention for their widespread occurrence and their toxic, mutagenic, and carcinogenic potentials (Freitag et al., 1985), sixteen un-substituted PAHs have been listed by the US Environmental Protection Agency (EPA) as priority pollutants. PAHs originated mainly from incomplete combustion of fossil fuels and other organic substances during industrial activities, residential heating, power generation, incineration, and vehicle emissions (Garban et al., 2002; Dyke et al., 2003; Mastral et al., 2003). Due to the consumption of the large amount of energy sources, the urban environment is a source region of PAHs.

The rapid development of Beijing has resulted in significant stress to Beijing environments. Among them, severe air pollution was caused by the enormous daily traffic, industrial and domestic emissions. The total-PAH concentration in the aerosol of Beijing was $178.99 \mu \mathrm{g} / \mathrm{g}$ in summer and $749.26 \mu \mathrm{g} / \mathrm{g}$ in winter (Okuda et al., 2002). The benzo[a]pyrene (BaP) concentration in outdoor air in residential areas of Beijing was approximately 15 times higher than that in residential areas of Tokyo (Ando et al., 1996) and BaP from the urban center site (Temple of Heaven) in autumn even exceeded the Chinese National Standards about 9 folds ( $\mathrm{Li}$ et al., 2001). However, the data of PAHs about the air is not abundant, which is partly attributed to the difficulties and high costs associated with air sampling. It was reported that PAH concentrations in soil were associated significantly with the corresponding levels in air (Vogt $e l$ al., 1987; Wild and Jones, 1995; Wild et al., 1990), house dust
(Chuang et al., 1995), urban street dust (Takada et al., 1990) and plants (Wang and Meresz, 1982), therefore, $\mathrm{PAH}$ determination in soil may provide important information on the environmental pollution state (Trapido et al., 1999), which will be helpful to the future development of study areas. A few studies have been published for soil in the typical areas in Beijing (e.g., highways, traffic line, residential and industrial areas)(Chu et al., 2003; Ge et al., 2004; Ma et al., 2003; Tang et al., 2005; Zheng et al., 1997). The grid sampling and analysis of the surface soil from outskirts of Beijing had been done for PAHs pollutants (Ma et al., 2005), but soil in the urban area with the many emission sources was excluded.

The aim of the study mainly concentrated on PAHs in the surface soil from the urban region of Beijing. The concentration, the spatial distribution, the compound profiles, and the possible sources of PAHs were examined and evaluated. The difference of PAHs between urban and outskirts was compared. Our study was significant for understanding the regional background of PAHs levels in the integrated Beijing, differing from types of anthropogenic input and evaluating the exposure level of sensitive populations living in Beijing.

\section{Material and methods}

\subsection{Material and reagents}

The mixed standard solution of 16 EPA-PAHs (naphthalene (Na); acenaphthylene (Acy); acenaphthene (Ace); fluorene (FI); phenanthrene (Phe); anthracene (An); fluoranthene (Flu); pyrene (Pyr); benz[a] anthracene $(\mathrm{BaA})$; chrysene (Chr); benzo[b] fluoranthene $(\mathrm{BbF})$; benzo $[\mathrm{k}]$ fluoranthene $(\mathrm{BkF})$; benzo[a]pyrene $(\mathrm{BaP})$; indeno $[1,2,3-\mathrm{cd}]$ pyrene $(\mathrm{InP})$; 
dibenz [a,h] anthracene (DBA); benzo[g,h,i]perylene (BghiP)) each at $1000 \mu \mathrm{g} / \mathrm{ml}$ were purchased from Aldrich (WIS, USA) and further diluted to obtain the desired concentration. The surrogate, 2-flurobiphenyl (2-FBP) was purchased from Supelco (Bellefonte, PA, USA). All solvents were of analytical purity (Beijing Chemical Factory, China) and redistilled in all-glass system before use. Silica gel (100-200 mesh) was purchased from Qingdao Ocean Chemical Company (China) and was activated in drying oven at $130^{\circ} \mathrm{C}$ for 16 h. Anhydrous sodium sulfate (Beijing Chemical Factory, China) was heated at $600^{\circ} \mathrm{C}$ for $12 \mathrm{~h}$.

\subsection{Sampling and preparation}

The main city zone of Beijing was surrounded by four ring roads by now. 30 soils at different locations within the four-ring road were sampled. The study area was divided into regular grids of $(4 \times 4) \mathrm{km}^{2}$, within which the topsoil samples $(5-30 \mathrm{~cm})$ were collected. Each of the composite soil samples was made of 16 sub-samples obtained in a $(1 \times 1) \mathrm{km}^{2}$ grid using a stainless steel hand auger. The detailed sampling locations are shown in Fig.1. The soil was air-dried in fume hood at room temperature, thoroughly mixed, sieved to 30 mesh and stored in glass bottles at $-4^{\circ} \mathrm{C}$ until further processing. The remaining water content in the soil was determined gravimetrically after drying individual sample in an oven at $105^{\circ} \mathrm{C}$ for $12 \mathrm{~h}$. All the results were reported as dried weight.

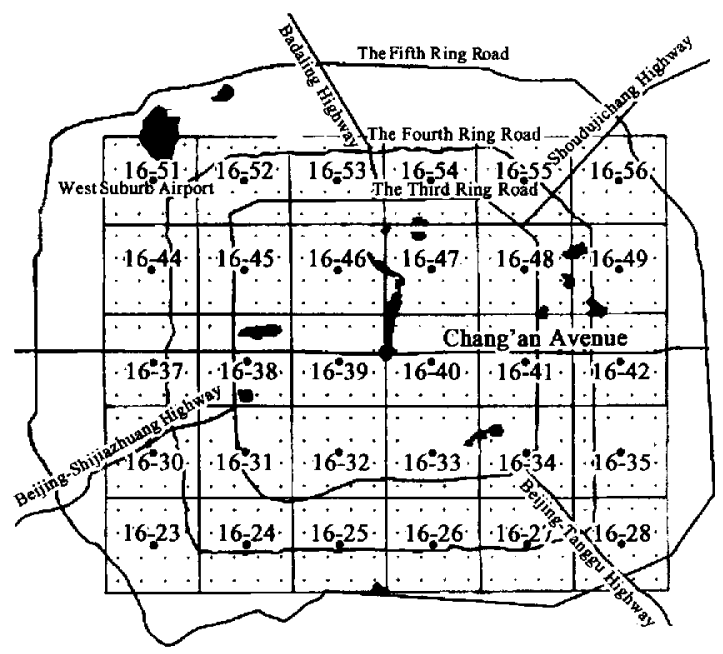

Fig.1 Geographic location of samples

\subsection{Sample extraction and clean-up}

Five gram was ground with anhydrous sodium sulfate into free flowing powder. The sample was ultrasonically extracted in centrifuge tube with $30 \mathrm{ml}$ of acetone-hexane $(1 / 1, \mathrm{v} / \mathrm{v})$ for $5 \mathrm{~min}$ and then the extact was separated by centrifugation. The process was repeated three times. The solvents were combined and evaporated using K-D apparatus with a gentle stream of nitrogen, then hexane was added as solvent. The concentrated extract was transferred to chromatograph column (30 cm $\times 10 \mathrm{~mm} \mathrm{I.D.)}$ containing $10 \mathrm{~g}$ of activated silica gel with $1 \mathrm{~g}$ of anhydrous sodium sulfate on the column top. The silica gel was soaked in dichloromethane and filled in the column. The column was pre-eluted with $40 \mathrm{ml}$ of hexane before loading the sample. The concentrated extract was transferred to the column top and was eluted by $25 \mathrm{ml}$ of $n$-hexane and followed by $50 \mathrm{ml}$ of hexane-dichloromethane $(1 / 1, \mathrm{v} / \mathrm{v})$. The second fraction was collected and evaporated, then was adjusted to $0.2 \mathrm{ml}$ for determination.

\subsection{PAHs determination}

The determination of PAHs was carried out with a Hewlett Parkard 6890 gas chromatography-5973 mass selective detector (GC-MS) system. The separation was performed on a fused silica capillary column (DB-5, $30 \mathrm{~m} \times 0.25 \mathrm{~mm}$ I.D., and $0.25 \mu \mathrm{m}$ film thickness). The carrier gas was helium. The ionization was performed in the electron impact mode at $70 \mathrm{eV}$ and the mass range scanned was from 50 to 550 amu under full scan acquisition mode. The GC oven temperature was programmed as follows: initial temperature $70^{\circ} \mathrm{C}$ held for $1 \mathrm{~min}$, increased to $290^{\circ} \mathrm{C}$ at a rate of $4^{\circ} \mathrm{C} / \mathrm{min}$ held for $2 \mathrm{~min}$, then increased to $300^{\circ} \mathrm{C}$ at a rate of $10^{\circ} \mathrm{C} / \mathrm{min}$, maintained for $20 \mathrm{~min} .1$ $\mu l$ of sample was injected in splitless mode. Peak identification of PAHs was made by comparison of retention times and mass-spectrum with corresponding standards.

Quality control was based on the following procedures. Method blank was firstly run. The matrix blanks, the recoveries of PAHs and the limits of detection were based on the measures of the underground 20-metere-depth soil samples from the rural area of Beijing. The average recoveries for $\sum 16$ EPA-PAHs in five times were from $86.7 \%-105.7 \%$ with less than $10 \%$ relative standard deviations. Before extraction, the soil sample was spiked with known amounts of 2-FBP as surrogate to compensate for the losses of PAHs. Recoveries for 2-FBP surrogate were $70 \%-115 \%$ (mean $89 \%$ ) and the values were satisfactory and no correction was applied to the samples. The limits of detection (LODs) for PAHs as three times response of signal-to-noise in matrix blank sample, ranged from 1.00 for $\mathrm{BaA}$ to $8.64 \mathrm{ng} / \mathrm{g}$ for Na. All data have been blank corrected.

Correlation analysis was performed with SPSS 11.5 for Windows. The characteristic ratio of individual PAH was drawn using origin 6.1. For the contour map, Surface Mapping System (Ver. 7.0, Golden software, CO, USA) was used.

\section{Results and discussion}

\subsection{PAHs concentrations in soil}


The minimum, maximum, mean, median values and standard deviations of PAHs concentrations are listed in Table 1 and all were calculated by dried weight. The mean concentration of individual PAH varied from $0.007 \mu \mathrm{g} / \mathrm{g}$ for Acy to $0.249 \mu \mathrm{g} / \mathrm{g}$ for Flu. $\mathrm{BaP}$, as one important representative toxic PAHs, was $0.023-0.402 \mu \mathrm{g} / \mathrm{g}$ with a median value of $0.075 \mu \mathrm{g} / \mathrm{g}$ and a mean value of $0.105 \mu \mathrm{g} / \mathrm{g}$. $\sum 2-3$ ring PAHs referred to the total concentrations of $\mathrm{Na}$, Acy, Ace, $\mathrm{Fl}, \mathrm{Ph}$ and $\mathrm{An}$ and ranged from 0.088 to $1.288 \mu \mathrm{g} / \mathrm{g}$ with $0.323 \mu \mathrm{g} / \mathrm{g}$ as mean. $\sum 4-6$ ring PAHs referred to the total concentrations of Flu, Pyr, BaA, Chr, BbF, $\mathrm{BkF}, \mathrm{BaP}, \mathrm{InP}, \mathrm{DBA}$ and BghiP and varied from 0.325 to $4.683 \mu \mathrm{g} / \mathrm{g}$ with $1.315 \mu \mathrm{g} / \mathrm{g}$ as mean. The concentrations of $\sum 7 \mathrm{Car}-\mathrm{PAHs}$ was the sum of $\mathrm{BaA}$, $\mathrm{BaP}, \mathrm{BbF}, \mathrm{BkF}, \mathrm{Chr}, \mathrm{DBA}$ and $\operatorname{InP}$ (US EPA, 2002) and was between 0.151 and $2.200 \mu \mathrm{g} / \mathrm{g}$ with 0.677 $\mu \mathrm{g} / \mathrm{g}$ as the mean. The concentration of the $\Sigma 16$ EPA-PAHs ranged from 0.467 to $5.470 \mu \mathrm{g} / \mathrm{g}$ with $1.637 \mu \mathrm{g} / \mathrm{g}$ as the mean concentration and $1.251 \mu \mathrm{g} / \mathrm{g}$ as the median. The contour map of the $\sum 16$ EPA-PAHs concentrations in the soil samples is shown in Fig.2. The map showed the spatial distribution characteristic of $\sum 16$ EPA-PAHs. It seemed that the levels of $\sum 16$ EPA-PAHs were more than $1.000 \mu \mathrm{g} / \mathrm{g}$ in the most of the sites and those about the $13 \%$ sites exceeded the range of the majority of urban soil concentrations $(0.600-3.000 \mu \mathrm{g} / \mathrm{g}$, WHO, 2000). As seen in Fig. 2, sites with the higher level of PAHs were not located in the urban center with dense vehicles and populations, but fell in the southwest and southeast regions beyond the Four-ring road and site with the highest level was found at station $16-33(5.470 \mu \mathrm{g} / \mathrm{g})$ located in the south of the Third-ring road. These may be accounted for by the fact that there were more PAHs inputs in these areas due to a large number of factories located, while types of industrial activities are the major factor of the consumption of energy source in Beijing. A large amount of waste gas/particle with PAHs from incomplete combustion of fossil fuel in industrial activities was emitted to atmosphere, then PAHs at atmosphere were transferrd to soil via dry/wet deposition. Due to the correlation of PAHs between in soil and in air (Vogt et al., 1987; Amagai et al., 1999; Trapido et al., 1999), it indicated that PAHs level in air in these regions should give prominence to be focused on.

The mean concentration of the individual $\mathrm{PAH}$ in urban soil from Beijing $(0.007-0.249 \mu \mathrm{g} / \mathrm{g})$ was greatly in excess of the background value in soil from the biosynthesis and forest fire $(0.001-0.01 \mu \mathrm{g} / \mathrm{g}$; Edwards, 1983) except for Acy, and much higher than those in the soil from the exurb of Beijing (Miyun and Fangshan districts) $(0.002-0.009 \mu \mathrm{g} / \mathrm{g} ; \mathrm{Gc}$ et $a l$, 2004). Compared with the surface soil from the
Table 1 Statistics description of PAHs in the soil of Beijing ( $\mu \mathrm{g} / \mathrm{g})$

\begin{tabular}{|c|c|c|c|c|c|}
\hline Compound & Min. & Max. & Mean & Median & $S D$ \\
\hline $\mathrm{Na}$ & 0.024 & 0.474 & 0.076 & 0.062 & 0.078 \\
\hline Acy & nd & 0.032 & 0.007 & 0.006 & 0.006 \\
\hline Acc & nd & 0.086 & 0.012 & 0.008 & 0.015 \\
\hline $\mathrm{Fl}$ & 0.006 & 0.065 & 0.017 & 0.014 & 0.012 \\
\hline Phe & 0.047 & 0.542 & 0.184 & 0.156 & 0.114 \\
\hline An & 0.006 & 0.109 & 0.026 & 0.020 & 0.023 \\
\hline Flu & 0.069 & 0.993 & 0.249 & 0.193 & 0.190 \\
\hline Pyr & 0.051 & 0.750 & 0.183 & 0.144 & 0.144 \\
\hline $\mathrm{BaA}$ & 0.026 & 0.412 & 0.121 & 0.084 & 0.096 \\
\hline $\mathrm{Chr}$ & 0.053 & 0.665 & 0.205 & 0.153 & 0.157 \\
\hline $\mathrm{BbF}$ & 0.036 & 0.543 & 0.169 & 0.130 & 0.126 \\
\hline $\mathrm{BkF}$ & 0.018 & 0.308 & 0.099 & 0.075 & 0.076 \\
\hline $\mathrm{BaP}$ & 0.023 & 0.402 & 0.105 & 0.075 & 0.088 \\
\hline $\operatorname{In} P$ & 0.012 & 0.181 & 0.057 & 0.044 & 0.039 \\
\hline DBA & nd & 0.138 & 0.033 & 0.026 & 0.032 \\
\hline BghiP & 0.010 & 0.330 & 0.093 & 0.069 & 0.074 \\
\hline$\sum 2-3$ ring $\mathrm{PAHs}$ & 0.088 & 1.288 & 0.323 & 0.261 & 0.226 \\
\hline$\sum 4-6$ ring PAHs & 0.325 & 4.683 & 1.315 & 0.990 & 0.996 \\
\hline$\sum 7 \mathrm{Car}-\mathrm{PAHs}$ & 0.151 & 2.200 & 0.677 & 0.493 & 0.515 \\
\hline$\sum 16$ EPA-PAHs & 0.467 & 5.470 & 1.637 & 1.251 & 1.147 \\
\hline
\end{tabular}

Notes: nd $=$ not detected; $S D=$ standard deviation

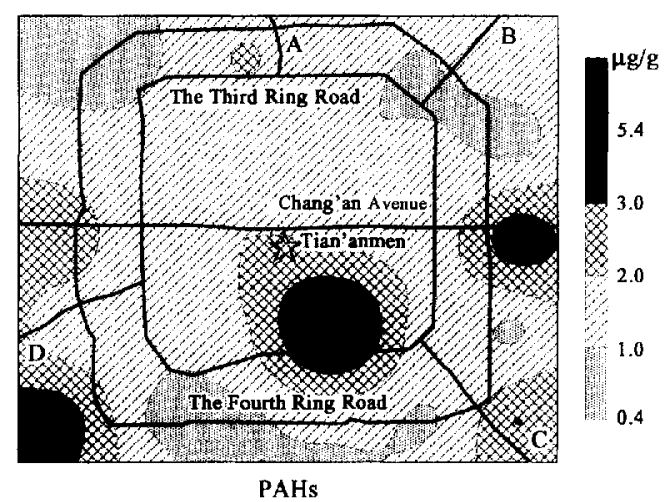

Fig. 2 The contour Map of $\sum 16$ EPA-PAHs in the urban soil of Beijing

outskirts of Beijing $(0.017-0.132 \mu \mathrm{g} / \mathrm{g}$; Ma et al., 2005 ), the concentration with the high molecular weight mass was obviously higher. However, the change trend of PAHs in urban area was basically consistent with that in the outskirts area (Fig.3), possibly suggesting the similar sources of PAHs in two areas. $\mathrm{BaP}$ was identified in all the samples. The mean $(0.105 \mu \mathrm{g} / \mathrm{g})$ was nearly two-fold higher than that in the outskirts of Beijing $(0.055 \mu \mathrm{g} / \mathrm{g}$; Ma et al., 2005) and even higher than that in the typical industrial and commercial region of Tokoyo in Japan (Matsushita et al., 1980). 


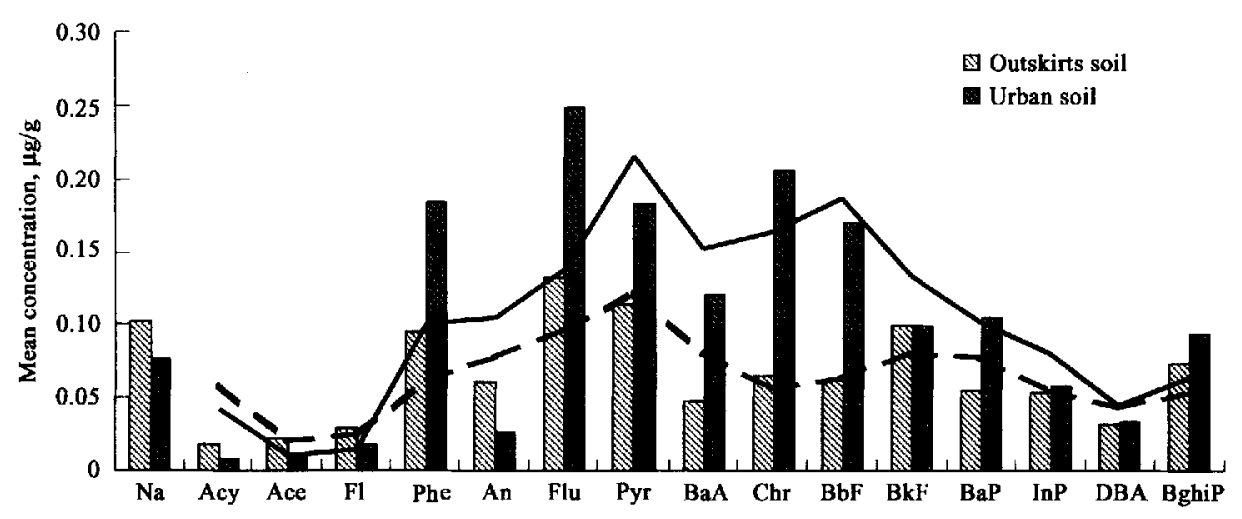

Fig.3 Composition of PAHs in soil from the outskirts and urban of Beijing

$\sum 16$ EPA-PAHs was ten-fold higher than the natural and background level of PAHs at remote or rural sites $(0.100 \mu \mathrm{g} / \mathrm{g}$; Trapido et al., 1999), suggesting that the urban soil of Beijing has been seriously contaminated by these pollutants. On the basis of the guideline of Dutch government, $\sum 16$ EPA-PAHs was much higher than the target value set for unpolluted soil $(0.02-0.05 \mu \mathrm{g} / \mathrm{g} \mathrm{dw}$; VROM, 1994) and that in site $16-33$ even exceeded $4 \mu \mathrm{g} / \mathrm{g}$ intervention value set for soil sanitation (Van Brummelen et al., 1996). Compared with the reports published in other urban region, the result was significantly lower than those presented in urban soil from New Orleans $(3.731 \mu \mathrm{g} / \mathrm{g}$ as median; Mielke $e t$ $a l ., 2001)$ and Estonian $((2.200 \pm 1.396) \mu \mathrm{g} / \mathrm{g}$; Trapido et $a l, 1999)$, was very close to the determined values from Tallinn, Heslsinki, Vilnius, Chicago and London (1.092 $\mu \mathrm{g} / \mathrm{g}$ as median; Saltiene el al., 2002), but it was higher than those in the adjacent countries to China and the adjoining cities to Beijing, e.g. Tokushima in Japan $(0.611 \mu \mathrm{g} / \mathrm{g}$ as mean; Yang et al., 2002), tropical metropolis Bangkok (0.012-0.380 $\mu \mathrm{g} / \mathrm{g}$; Wilcke et al., 1999), Chiang-Mai in Thailand $(0.824 \mu \mathrm{g} / \mathrm{g}$ as mean; Amagai et al., 1999) and Tianjin City of China $(0.818 \mu \mathrm{g} / \mathrm{g}$ as mean; Wang et al., 2003). It was reported that PAHs in soils from urban areas were approximately $2-10$ higher than those in rural areas (Lodovici et al., 1994; Tremolada et al., 1996; Wagrowski and Hites, 1997). Here, the mean of $\sum 16$ EPA-PAHs $(1.637 \mu \mathrm{g} / \mathrm{g})$ was nearly 4 times higher than that in the rural area $(0.464 \mu \mathrm{g} / \mathrm{g}$; Ma et al., 2005) and was much higher than those from the exurb of Beijing $(0.058-0.141 \mu \mathrm{g} / \mathrm{g}$; Ge et al., 2004). It appeared that the pollution situation of PAHs in Beijing urban soil was more serious than those in the adjacent areas.

\subsection{PAHs compound profiles}

The relative PAH composition in soil is displayed in Fig.4. Flu were the most abundant components (16\%), followed by $\mathrm{Chr}(13 \%)$, Pyr (11\%), Phe (11\%) and $\mathrm{BbF}(10 \%)$. BaP formed $6 \%$ of $\sum 16$ EPA-PAHs. PAHs by ring size were predominant by 4 - and 5-ring
PAHs. In general, the $\sum 4-6$ ring PAHs consisted of about $79.0 \%$ of $\sum 16$ EPA-PAHs, while $\sum 2-3$ ring PAHs only accounted for $21 \%$. The seven potential carcinogenic PAHs represent $29 \%-51 \%$. This might be related with the fact that PAHs with higher rings tend to be strongly adsorbed to the soil and lower molecular PAHs was apt to be depleted preferentially. The composition in this study area was similar to those in urban atmospheric particulates of Beijing (Huang et al., 2001; Zeng et al., 2001, 2002; Liu et al., 2003), thus our study should be beneficial to understand the pollution of PAHs in the air. As reported, soil played a role of accumulator of PAHs in the air and PAHs concentrations in soil were associated significantly with the corresponding levels in air (Vogt et al., 1987; Amagai et al., 1999; Trapido et al., 1999).

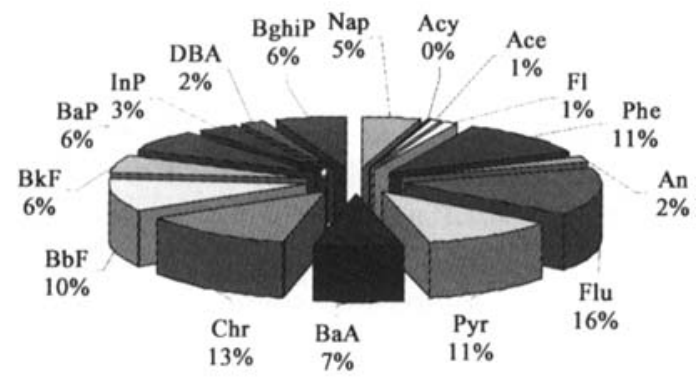

Fig.4 Relative PAH composition $(\%, w / w)$ of 16 EPA-PAHs

A liner regression analysis was done among the individual PAH and $\sum 16$ EPA-PAHs. Most of the individual PAH yielded a good correlation $(r>0.5)$. There existed stronger correlations between lower molecular PAH (Na, Acy, Ace, Fl, Ph and An, $r>0.6$ ) and between the high molecular PAH (Flu, Pyr, BaA, $\mathrm{Chr}, \mathrm{BbF}, \mathrm{BkF}, \mathrm{BaP}, \mathrm{Per}, \mathrm{InP}, \mathrm{DBA}$ and BghiP, $r>0.8$ ), respectively. There was also a better correlation between individual PAH and $\sum 16$ EPAPAHs $(r>0.6)$ except for $\mathrm{Na}$ and Ace. The better correlation might attribute to the similar source of PAHs at different sampling sites (Ma et al., 2005; Weiss et al., 1994; Wilcke and Zech, 1997). BaP, the 
most potent carcinogenic PAHs, was significantly correlated with $\sum 16$ EPA-PAHs $(r=0.95)$ and may be used to estimate total PAHs concentrations in the soil due to the similarity of each other.

\subsection{Source of PAHs}

Petrogenic and pyrolytic sources are by far the most important source of PAH inputs to the environment (Back et al., 1991). Petrogenic input is closely related to petroleum products (e.g., oil spills, road construction materials) and pyrolytic sources include combustion processes (e.g., fossil fuel combustion, forest fires, shrub and grass fires). Due to the lack of the characteristic parameters of PAHs in soil, those at atmosphere were generally used to discuss the PAHs source in soil (Trapido, 1999; Saltiene et $a$., 2002; Zhang et al., 2004; Ma et al., 2005; Tang el al., 2005). The ratios of low to high molecular weight PAHs (LPAHs/ HPAHs), anthracene to anthracene plus phenanthrene $(\mathrm{An} /(\mathrm{An}+\mathrm{Phe}))$ and fluoranthene to fluoranthene plus pyrene (Flu/ $($ Flu + Pyr $)$ ) was generally used as a tool for discriminating the petroleum/combustion sources of PAHs (Sicre et al., 1987; Budzinski et al., 1997; Zılang et al. , 2004). In general, the petroleum source contain relatively higher concentrations of $2-3$ ring PAHs compounds (Tolosa el al., 1996), while a large proportion of high molecular weight parent PAHs is typical characteristic of a combustion origin (Budzinski et al., 1997). An/ (An+Phe) <0.10 usually is considered as an indication of petroleum while a ratio of $>0.10$ indicates a dominance of combustion (Budzinski et al., 1997). Most cruel oil samples have Flu' (Flu+Pyr) ratio below 0.40 and combustion generated PAHs are above 0.40. In our study, the HPAHs were definite dominant and the LPAHs/HPAHs ranged from $0.13-0.72$ with the average ratio of $0.28, \mathrm{An} /(\mathrm{An}+\mathrm{Phe})$ was $0.05-0.18$ with a mean of 0.12 and Flu/(Flu+Pyr) was $0.55-$ 0.62 with a mean of 0.58 , which suggested the definite predominance of combustion source in the urban soil of Beijing.

$\mathrm{BaP} / \mathrm{BghiP}$ could be used to distinguish from traffic exhausts and coal combustion sources. The ratio of $\mathrm{BaP} / \mathrm{BghiP}$ between $0.3-0.44$ indicated the traffic exhausts and that between $0.9-6.6$ showed the coal combustion (Sawicki, 1962). In addition, the ratio of $\mathrm{Flu} /(\mathrm{Flu}+\mathrm{Pyr})$ between 0.40 and 0.50 was considered as being more characteristic of liquid fossil fuel (vehicle and crude oil) combustion whereas the ratio above 0.50 is characteristic of grass, wood or coal combustion (Yunker et al., 2002). In the present study, the ratio of $\mathrm{BaP} / \mathrm{BghiP}$ ranged from 0.3 to 5.1 with 1.2 as the mean and $90 \%$ values were in the range of $0.9-6.6$. All values of $\mathrm{Flu} /(\mathrm{Flu}+\mathrm{Pyr})$ were $>$ 0.5 . Plot of $\mathrm{BaP} / \mathrm{BghiP}$ versus Flu/(Flu $+\mathrm{Pyr})$ was shown in Fig.5. As seen in Fig.5, 90\% of samples fell in the combustion zone (I), suggesting the prominence of coal combustion around the study area. Three samples with Flu/(Flu+Pyr) $>0.5$ and BaP/BghiP $<$ 0.9 indicated the mixture (II) of coal combustion and traffic emission.

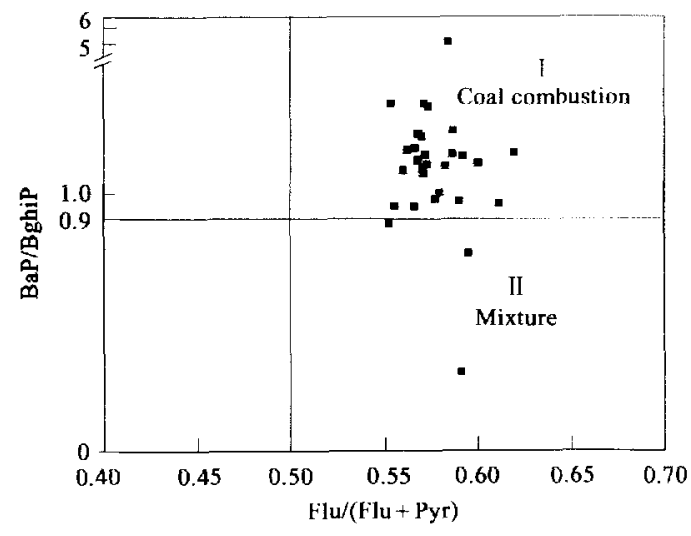

Fig.5 Plot of BaP/BghiP versus Flu/(Flu 1 Pyr $)$

Through the analysis of PAHs characteristic ratio, it can be concluded that pyrolysis source, especially coal combustion, was the main contamination sources of PAHs in soil from the urban area of Beijing. However, due to the PAHs source in soil were discussed by the characteristic parameters at atmosphere, some error were probably made by the different environmental medium. This result was not in accordance with those in other metropolitan areas, which generally considered traffic as the main source of PAHs in environment (Rogge et al., 1993; Van Metre et al., 2000), but it was fit for the real condition in Beijing and could be accounted for by the energy consumption and the structure of energy sources in Beijing. Beijing's energy consumption pointed to a total of over $41 \times 10^{6} \mathrm{t}$ of standard coal in 2000 , of which coal and hard coke took up 74.2 percent forming the main cause of pollution to Beijing's atmosphere and local environment (Zeng et al., 2001, 2002; Liu et al., 2003; Zhang et al., 2004). However, He et al. (2001) reported that the vehicle in Beijing grows at a rate of $15 \%$ per year through the $1990 \mathrm{~s}$, and have exceeded $2.0 \times 10^{6}$ in 2000 . Traffic exhaust had been considered as one of the predominated sources of contamination to PAHs in Beijing (Zeng et al, 2001, 2002; Liu et al., 2003) and Okuda et al. (2002) even concluded that traffic exhaust was major pollution source in the atmosphere of Beijing. In our study, the mean of $\mathrm{BaP} / \mathrm{BghiP}$ was 1.2 and was only slightly higher than the transition point of coal combustion/traffic exhaust (0.9). In addition, BghiP, as a known marker of traffic exhausts (Baek et al., 1991 ), with an average of $6.2 \%$ of the $\sum 16$ EPAPAHs, also reflected the importance effect of the traffic source in urban soils of Beijing. This indicated that controlling the coal usage should be emphasized on but the effect of increasing vehicles should not be 
ignored for cutting the pollution of PAHs in Beijing.

\section{Conclusions}

This work revealed the soil contamination information by PAHs residues in urban area of Beijing. It extends our understanding of the current PAHs contamination status in whole the Beijing area. The absolute concentrations of $\sum 16$ EPA-PAHs and BaP showed that pollution of PAHs in urban soil of Beijing was serious but most fell in the range of the majority of urban soil concentrations. PAHs in the most sites had a similar source. PAHs characteristic ratios showed that the coal combustion was the dominant sources of PAHs and traffic exhausts was not negligible. This study suggested that the pollution of PAHs in urban area of Beijing should emphasize on controlling the coal combustion and traffic exhaust, especially the coal combustion.

Acknowledgements: The authors greatly thank Prof. Daren Zhang and Agilent Technologies Co. Ltd (China) for performing the experiments.

\section{References:}

Amagai T, Takahashi Y, Matsushita H M D et al., 1999. A Survey on polycyclic aromatic hydrocarbon concentrations in soil in Chiang-Mai, Thailand [J]. Environ Int, 25: 563-572.

Ando M, Katagiri K, Tamura K et al, 1996. Indoor and outdoor air pollution in Tokyo and Beijing supercities [J]. Atmos Environ, 30: 695-702.

Baek S, Field R A, Goldstone M E, 1991. A review of atmospheric polycyclic aromatic hydrocarbons: Sources, fate and behavior [J]. Water, Air \& Soil Pollut, 60: 279-300.

Budzinski H, Jones I, Bellocq J et al., 1997. Evaluation of sediment contamination by polycyclic aromatic hydrocarbons in the Gironde estuary [J]. Mar Chem, 58: 85-97.

Chu S G, Liu H, Ma L L et al, 2003. Polycyclic aromatic hydrocarbons in soil adjacent to highways in Beijing, People's Republic of China [J]. Bull Environ Contam Toxicol, 70: 972-977.

Chuang J C, Callahan P J, Menton R G et al., 1995. Monitoring methods for polycyclic aromatic hydrocarbons and their distribution in house dust and track-in soil [J]. Environ Sci Technol, 29: 494-500.

Dyke P H, Foan C, Fiedler H, 2003. PCB and PAH releases from power stations and waste incineration processes in the UK [J]. Chemosphere, 50: 469-480.

Edwards N T J, 1983. Polycyclic aromatic hydrocarbons (PAHs) in the terrestrial environment-a review [J]. J Environ Qual, 12: 427441.

Freitag D, Ballhorn L, Geyer H el al., 1985. Environmental hazard profile of organic chemicals: An experimental method for the assessment of the behaviour of organic chemicals in the ecosphere by means of simple laboratory tests with ${ }^{14} \mathrm{C}$ labelled chemicals [J]. Chemosphere, 14: 1589-1616.

Garban B, Blanchoud H, Motelay-Massei A et al., 2002. Atmospheric bulk deposition of PAHs onto France: trends from urban to remote sites [J]. Atmos Environ, 36: 5395-5403.

Ge X L, Xie W M, Luo S G el $a$., 2004. Distribution and composition of polycyclic aromatic hydrocarbond in soil of Miyun and Fangshan area, Beijing [J]. Rock and Mineral Analysis, 23: $132-136$

He K, Yang F, Ma Y et al., 2001. The characteristics of $\mathrm{PM}_{2 .}$ in Beijing, China [J]. Atmos Environ, 35: 4959-4970.

Huang Y R, Di Y A, Shi J H et al., 2001. PAHs and normal-alkanes in urban air of Beijing, Tokyo and Tsukuba [J]. Res Environ Sci, 14: $4-8$.
Li R Q, Zhang Z Q, Shi J H el al,, 2001. The analysis of organic compounds of atmospheric aerosols in Beijing [J]. Res Environ Sci, $14: 21-28$.

Liu D M, Li Y Y, Jiang B K et ral., 2003. Preliminary study of organic pollutants from atmospheric particulates in Shougang District, Beijing [J]. Earth Science-Journal of China University of Geosciences, 28: 327-332.

Lodovici M, Dolara P, Taiti S et al., 1994. Polynuclear aromatic hydrocarbons in the leaves of the evergreen tree (Laurus nobilis) [J]. Sci Total Environ, 153: 61--68.

Ma L L, Chu S G, Wang X T et al., 2005. Polycyclic aromatic hydrocarbons in the surface soils from outskirts of Beijing, China [J]. Chemsphere, 58: 1355-1363.

Ma L L, Chu S G, Xu X B, 2003. Organic contamination in the greenhouse soils from Beijing suburbs, China [J]. J Environ Monit, 5; 786-790.

Mastral A M, López J M, Callen M S et al., 2003. Spatial and temporal PAH concentrations in Zaragoza, Spain [J]. Sci Total Environ, 307: 111-124.

Matsushita H, Kato Y, Hisamatsu Y, 1980. Distribution of benzo [a] pyrene content in soil in urban area [J]. J Jpn Soc Air Pollut, 15: $348-352$.

Mielke H W, Wang G, Gonzales C R et al., 2001. PA.H and metal mixtures in New Orleans soils and sediments [J]. Sci Total Environ, 281: 217-227.

Okuda T, Kumata $\mathrm{H}$, Naraoka $\mathrm{H} e t$ al., 2002. Origin of atmospheric polycyclic aromatic hydrocarbons (PAIls) in Chinese cities solved by compound-specific stable carbon isotopic analyses [J]. Org Geochem, 33: 1737-1745.

Rogge W F, Hildemann L M, Mazurek M A et al., 1993. Sources of fine organic aerosol 2. Noncatalyst and catalyst-equipped automobiles and heavyduty diesel trucks [J]. Environ Sci Technol, 27:636651.

Saltiene Z, Brukstiene D, Ruzgyte A, 2002. Contamination of soil by polyaromatic hydrocarbons in some urban areas [J]. Polycycl Aromat Comp, 22: 23-35.

Sawicki E, 1962: Analysis for airborne particulate hydrons. Their relative proportion affected by different types of pollution [J]. Nat Cancer Inst Monograph, 9: 201-208.

Sicre M A, Marty J C, Saliot A et al., 1987. Aliphatic and aromatic hydrocarbons in different sized aerosols over the Mediterranean Sea: occurrence and origin [J]. Atmos Environ, 21: 2247-2259.

Takada H, Onda T, Ogura N, 1990. Determination of polycyclic aromatic hydrocarbons in urban street dust and their source material by capillary gas chromatography [J]. Environ Sci Technol, 24: 1179-1186.

Tang L, Tang X Y, Zhu Y G et al., 2005. Contamination of polyaromatic hydrocarbons (PAHs) in urban soil in Beijing, China [J]. Environ Int, 31: 822-828.

Tolosa I, Bayona J M, Albaigés J, 1996. Aliphatic and polycyclic aromatic hydrocarbons and sulfur/oxygen derivatives in northwestern mediterranean sediments: spatial and temporal variability, fluxes, and budgets [J]. Environ Sci Technol, 30: 2495-2503.

Trapido M, 1999. Polycyclic aromatic hydrocarbons in Estonian soil: contamination and profiles [J]. Environ Pollut, 105: 67-74.

Tremolada P, Burnett V, Calamari D el al., 1996. Spatial distribution of PAHs in the UK atmosphere using pine needles [J]. Environ Sci Technol, 30: 3570-3577.

USEPA, 2002. Polycyclic Organic Matter. US Environmental Protection Agency [S]. Available from: http://www.epa gov/ttn/atw/hlthef/polycycl.html.

Van Brummelen T C, Verweij R A, Wedzinga S A et al., 1996. Enrichment of polycyclic aromatic hydrocarbons in forest soil near a blast furnace plant [J]. Chemosphere, 32: $293-314$.

Van Metre P C, Mahler R J, Furlong E T, 2000. Urban sprawl leaves its PAH signature [J]. Environ Sci Technol, 34: 4064-4070.

Vogt N B, Brakstad F, Thrane K et al., 1987. Polycyclic aromatic hydrocarbons in soils and air: Statistical analysis and classification by the SIMCA method [J]. Environ Sci Technol, 


$$
21: 35-44
$$

VROM, 1994. Environmental quality objectives in the Netherlands[M]. Ministry of Housing, Spatial Planning and Environment.

Wagrowski D M, Hites R A, 1997. Polycyclic aromatic hydrocarbon accumulation in urban, suburban, and rural vegetation $[\mathrm{J}]$ Environ Toxicol Chem, 31:279-288.

Wang D T, Meresz O, 1982. Occurrence and potential uptake of polynuclear aromatic hydrocarbons of highway traffic origin by proximal grown food crops [M]. In: Polynuclear aromatic hydrocarbons: physical and biological chemistry (Cooke, M., Dennis, A. J., ed.). Columbus, NY: Batelle Press. 885-896.

Wang X, Zheng Y, Liu R et al., 2003. Medium scale spatial structures of polycyclic aromatic hydrocarbons in the topsoil of Tianjin area [J]. Journal of Environmental Science \& Health, Part BPesticides, Food Contaminants, \& Agricultural Wastes, 38: $327-335$.

Weiss $\mathrm{P}$, Riss $\mathrm{A}$, Gschmeidler $\mathrm{E}$ ol $\alpha$ l., 1994. Investigation of heavy metal, PAH, PCB patterns and PCDD/F profiles of soil samples from an industrialized urban area (Linz, Upper Austria) with multivariate statistical methods [J]. Chemosphere, 29: $2223-$ 2236.

WHO Regional Office for Europe, Copenhagen, Denmark [Z], 2000. Chapter 5.9. PAHs Air Quality Guidelines - Second ed.

Wilcke W, Zech W, 1997. Polycyclic aromatic hydrocarbons (PAHs) in forest soil of the northern Czech mountains [J]. Z Pflanzenernähr Bodenkd, 160: 369-378.

Wilcke W, Müller S, Kanchanakool N et al., 1999. Polycyclic aromatic hydrocarbons in hydromorphic soils of the tropical metropolis Bangkok [J]. Geoderma, 91: 297-309.

Wild S R, Joncs K C, 1995. Polynuclear aromatic hydrocarbons in the
United Kingdom environment: a preliminary source inventory and budget [J]. Environ Pollut, 88: 91-108.

Wild S R, Waterhouse K S, McGrath S P et al., 1990. Organic contaminants in an agricultural soil with a known history of sewage sludge amendments: polycyclic aromatic hydrocarbons [J]. Environ Sci Technol, 24: 1706-1711.

Yang Y, Zhang X X, Korenaga T, 2002. Distribution of polynuclear aromatic hydrocarbons (PAHs) in the soil of Tokushima, Japan [J]. Water, Air \& Soil Pollut, 138:51-60.

Yunker M B, Macdonald R W, Vingarzan R et al., 2002. PAHs in the Fraser River basin: a critical appraisal of PAH ratios as indicators of PAH source and composition [J]. Org Geochem, 33: 489515.

Zeng F G, Li H, Wang Q et al, 2001. The characteristics and origin of the organic pollutants in the air of Beijing Shijingshan District [J]. Res Environ Sci, 14: 17-20.

Zeng F G, Wang G Y, Tian J $e$ t al., 2002. Pollution characteristics and source apportionment of PAHs in atmospheric acrosols of some regions in Beijing [J]. ACTA Scientiac Circumstantial, 22: 284288

Zhang Z L, Huang J, Yu G et al., 2004, Occurrence of PAHs, PCBs and organochlorine pesticides in Tonghui River of Beijing, China [J]. Environ Pollut, 130: 249-261

Zheng D W, Fang F, Zheng J Y et al., 1997. Research on distribution characteristics of polycyclic aromatic hydrocarbons in main traffic line crosses of Beijing urban district [J]. J Beijing Polytechnic University, 33: 30-34.

(Received for review October 17, 2005. Accepted February 10, 2006) 